\title{
Evaluation of Endotracheal Tube Scraping on Airway Resistance
}

\author{
J Brady Scott MSc RRT-ACCS AE-C FAARC, \\ Meagan N Dubosky MSc RRT-ACCS RRT-NPS AE-C, David L Vines, MHS RRT FAARC, \\ Adewunmi S Sulaiman MSc RRT, Kyle R Jendral MSc RRT-ACCS AE-C, \\ Gagan Singh MSc RRT-ACCS, Ankeet Patel MSc RRT-ACCS, Carl A Kaplan MD, \\ David P Gurka MD PhD, and Robert A Balk MD
}

\begin{abstract}
BACKGROUND: Spontaneous breathing trials (SBTs) are used to assess the readiness for discontinuation of mechanical ventilation. When airway resistance $\left(\mathbf{R}_{\mathrm{aw}}\right)$ is elevated, the imposed work of breathing can lead to prolongation of mechanical ventilation. Biofilm and mucus build-up within the endotracheal tube (ETT) can increase $R_{a w}$. Scraping the ETT can remove the biofilm build-up and decrease mechanical $\mathbf{R}_{\mathrm{aw}}$. The primary aim of this study was to evaluate the impact of ETT scraping on $\mathbf{R}_{\mathrm{aw}}$. The secondary aim was to determine whether decreasing $\mathbf{R}_{\mathrm{aw}}$ would impact subsequent SBT success. METHODS: Intubated, mechanically ventilated subjects were enrolled if they failed an SBT and had an $R_{\mathrm{aw}}$ of $>10 \mathrm{~cm} \mathrm{H} \mathrm{H}_{2} \mathrm{O} / \mathrm{L} / \mathrm{s}$. SBT failure was based on institutional guidelines, and $R_{\mathrm{aw}}$ was calculated by subtracting the difference between the measured peak and plateau pressures using a square flow waveform with an inspiratory flow set at $60 \mathrm{~L} / \mathrm{min}$. The endOclear device was inserted into the ETT and withdrawn per manufacturer's guidelines. Scraping was repeated until the ETT was cleared. Change in $\mathbf{R}_{\mathrm{aw}}$ was compared pre- and post-ETT scraping using a paired $t$ test. A Mann-Whitney $\mathrm{U}$ test evaluated the difference in percentage change in $R_{a w}$ between SBT groups. RESULTS: Twenty-nine subjects completed the study. The mean pre- and post-ETT scraping $R_{\text {aw }}$ values were $15.17 \pm 3.83$ and $12.05 \pm 3.19 \mathrm{~cm} \mathrm{H} \mathrm{H}_{2} \mathrm{O} / \mathrm{L} / \mathrm{s}$, respectively $(P<.001)$. Subsequent $\mathrm{SBT}$ success was $48 \%$; however, there was no difference in percentage change in $R_{\text {aw }}$ between subsequent passed SBT (18.61\% [interquartile range 8.90-33.93\%] ) and failed SBT $(23.88 \%$ [interquartile range $0.00-34.80 \%$ ] $), U=78.5, z=-0.284$, $P=.78$. No adverse events were noted with ETT scraping. CONCLUSIONS: This study demonstrated that ETT scraping can reduce $\mathbf{R}_{\mathrm{aw}}$. The decrease in $\mathbf{R}_{\mathrm{aw}}$ post-ETT scraping did not affect subsequent SBT success. Key words: mechanical ventilation; resistance; spontaneous breathing trial; biofilm; endotracheal extubation; work of breathing; airway obstruction; endotracheal tube; endotracheal tube obstruction; secretion removal. [Respir Care 2017;62(11):1423-1427. (C) 2017 Daedalus Enterprises]
\end{abstract}

Introduction

A spontaneous breathing trial (SBT) is the evaluation of a patient's ability to balance the respiratory load or work

Mr Scott, Ms Dubosky, Mr Vines, Mr Singh, Mr Patel, and Dr Kaplan are affiliated with the Division of Respiratory Care, Department of Cardiopulmonary Sciences, Rush University, Chicago, Illinois. Mr Sulaiman is affiliated with Northwestern Memorial Hospital, Chicago, Illinois. Mr Jendral is affiliated with Summa Health in Akron, Ohio. Drs Gurka and Balk are affiliated with the Division of Pulmonary and Critical Care Medicine, Department of Internal Medicine, Rush University Medical Center, Chicago, Illinois. of breathing (WOB) with his or her respiratory capacity to do the work. Due to factors that cause a load/capacity

\footnotetext{
Mr Scott presented a version of this paper as an Editor's Choice abstract at AARC Congress 2016, held October 15-18, 2016, in San Antonio, Texas.

Endoclear LLC supplied the endOclear devices free of charge. Mr Scott discloses relationships with Bayer Pharmaceuticals, Aerogen, and Sunovion Pharmaceuticals. Ms Dubosky discloses relationships with Halyard and Aerogen. Mr Vines discloses relationships with Teleflex, Aerogen, Carefusion, Covidien, Bayer Healthcare, Boehringer Ingelheim, Halyard, and Ohio Medical. Dr Balk discloses relationships with Ohio Medical, Roche Scientific, Thermo Fisher Scientific, bioMerieux, CDC, Immunexpress, and Asahi Kasei. The other authors have disclosed no conflicts of interest.
} 
imbalance (eg, increased airway resistance $\left[\mathrm{R}_{\mathrm{aw}}\right]$, decreased lung compliance), it is important that clinicians avoid suboptimal conditions when performing SBTs. An example is mucus buildup in the endotracheal tube (ETT), which results in luminal narrowing of the tube. It is thought that this narrowing imposes an unnecessary increase in the WOB due to the increase in $\mathrm{R}_{\mathrm{aw}}{ }^{1}$ Efforts have been made to understand the degree of this ETT luminal narrowing. Mietto et $\mathrm{al}^{2}$ measured this by using high-resolution computed tomography, noting that ETT narrowing is common and correlates with an increase in air-flow resistance. This narrowing occurred despite adequate humidification and suctioning.

Endotracheal tube scrapers have been described in the literature as devices that may be able to restore the original internal diameter of the ETT by removing accumulated secretions and biofilm..$^{3,4}$ At our institution, we utilize the endOclear (Endoclear LLC, San Ramon, California) to clear secretions when ETT obstructions are suspected. Although we have used it safely, it is unknown what impact its use has had on $\mathrm{R}_{\mathrm{aw}}$ and overall WOB in spontaneously breathing patients. Furthermore, it is unclear whether the resolution of the associated increase in $\mathrm{R}_{\mathrm{aw}}$ and WOB has any impact on subsequent SBT success in our institution.

An inspiratory $\mathrm{R}_{\mathrm{aw}}$ of $<10 \mathrm{~cm} \mathrm{H}_{2} \mathrm{O} / \mathrm{L} / \mathrm{s}$ is considered acceptable in intubated patients. ${ }^{5}$ We sought to evaluate the impact of ETT scraping on $\mathrm{R}_{\mathrm{aw}}$ in subjects with a measured $\mathrm{R}_{\mathrm{aw}}$ of $>10 \mathrm{~cm} \mathrm{H}_{2} \mathrm{O} / \mathrm{L} / \mathrm{s}$. The secondary aim of this study was to determine whether decreasing imposed work of breathing impacted success of the subsequent SBT.

\section{Methods}

This prospective observational study was conducted between December 2013 and October 2015 at Rush University Medical Center, a large urban academic medical center located in Chicago, Illinois. The study protocol, including waiver of consent, was approved by our institutional review board. Waiver of consent was requested after the study was initially approved, because the endOclear device was being used on mechanically ventilated patients with an increased $R_{a w}$ in our institution. Subjects were

Supplementary material related to this paper is available at http:// www.rcjournal.com.

Correspondence: J Brady Scott MSc RRT-ACCS AE-C FAARC, Division of Respiratory Care, Department of Cardiopulmonary Sciences, Rush University, Armour Academic Center, 600 S Paulina, 751 AAC, Chicago, IL 60612. E-mail: jonathan_b_scott@rush.edu.

DOI: $10.4187 /$ respcare. 05391

\section{QUICK LOOK}

\section{Current knowledge}

Biofilm and mucus build-up within the endotracheal tube (ETT) can increase airway resistance $\left(\mathrm{R}_{\mathrm{aw}}\right)$. When $\mathrm{R}_{\mathrm{aw}}$ is elevated, the imposed work of breathing can lead to prolongation of mechanical ventilation. Cleaning an ETT with a tube scraper can remove the biofilm buildup, restore ETT patency, and decrease mechanical $R_{a w}$.

\section{What this paper contributes to our knowledge}

Using a tube scraper to remove secretions from an ETT can reduce mechanical $R_{a w}$ by a statistically significant amount.

included if they failed at least one SBT as documented in the electronic medical record and had an $\mathrm{R}_{\mathrm{aw}}>10 \mathrm{~cm} \mathrm{H}_{2} \mathrm{O} / \mathrm{L} / \mathrm{s}$. $\mathrm{R}_{\mathrm{aw}}$ was measured by temporarily changing the ventilator mode to continuous mandatory ventilation in a square flow waveform at $60 \mathrm{~L} / \mathrm{min}$ and calculating the difference between the peak and plateau airway pressures.

Spontaneous breathing trials are performed daily by the respiratory therapists per physician order at our institution after they have been assessed for extubation readiness. Qualifiers for SBT failure include an increased respiratory rate, tachycardia attributed to SBT, complaint of distress, anxiety, and a rapid shallow breathing index $>105$ (see Appendix 1 in the supplementary materials at http://www.rcjournal.com). Study staff were notified by respiratory therapists when mechanically ventilated adults failed at least one SBT. Members of the study team confirmed the SBT failure based on documentation in the electronic medical record.

\section{Tube Clearance Procedure}

Ventilator data, including peak and plateau pressure, was recorded pre- and post-tube scraping to assess changes in the calculated $\mathrm{R}_{\mathrm{aw}}$. $\mathrm{R}_{\mathrm{aw}}$ was measured as described above. Subject assessment data were also recorded pre- and post-tube scraping to assess subject safety and tolerance with the tube scraping procedure. Data included breathing frequency, tidal volume, rapid shallow breathing index, heart rate, blood pressure, and accessory muscle use.

During the tube clearance procedure, study subjects were hyperoxygenated and suctioned via in-line suction catheter as per department policy. That policy dictates that the catheter should be advanced until resistance is met and then withdrawn slowly for a duration no longer than $15 \mathrm{~s}$ while applying negative pressure. The endOclear device was inserted and deployed into the ETT until it was $1 \mathrm{~cm}$ above the terminal end of the tube. This placement was 


\section{Evaluation of ETT Scraping on Airway Resistance}

Table 1. Subject Information

\begin{tabular}{|c|c|c|c|c|c|c|}
\hline Subject & ETT Size & Primary Diagnosis & $\begin{array}{l}\text { Duration of Mechanical } \\
\text { Ventilation (h) }\end{array}$ & $\begin{array}{c}\text { Pre- } \mathrm{R}_{\mathrm{aw}} \\
\left(\mathrm{cm} \mathrm{H}_{2} \mathrm{O} / \mathrm{L} / \mathrm{s}\right)\end{array}$ & $\begin{array}{l}\text { Post- } \mathrm{R}_{\mathrm{aw}} \\
\left.\text { (cm H} \mathrm{H}_{2} \mathrm{O} / \mathrm{L} / \mathrm{s}\right)\end{array}$ & $\begin{array}{l}\text { Subsequent SBT } \\
\quad(\text { Pass/Fail })\end{array}$ \\
\hline 1 & 6.5 & Neurologic & 86 & 15 & 15 & No follow-up \\
\hline 2 & 7 & Respiratory (pulmonary sarcoidosis) & 55 & 22 & 20 & No follow-up \\
\hline 3 & 7 & Neurologic & Unknown & 17 & 11 & Fail \\
\hline 4 & 7 & Septic & 288 & 21 & 13 & Pass \\
\hline 5 & 7 & Cardiac & 63 & 12 & 12 & Fail \\
\hline 6 & 7 & Respiratory (pulmonary embolism) & 192 & 24 & 19 & Fail \\
\hline 7 & 7 & $\begin{array}{l}\text { Respiratory (lung cancer with } \\
\text { pneumonia) }\end{array}$ & 179 & 13 & 13 & Fail \\
\hline 8 & 7 & Other & 65 & 15 & 14 & Pass \\
\hline 9 & 7.5 & Respiratory (COPD exacerbation) & 54 & 13 & 13 & Fail \\
\hline 10 & 7.5 & $\begin{array}{l}\text { Respiratory (hypercarbic respiratory } \\
\text { failure) }\end{array}$ & 38.5 & 14 & 10 & Pass \\
\hline 11 & 7.5 & $\begin{array}{l}\text { Respiratory (hypercarbic respiratory } \\
\text { failure) }\end{array}$ & 24 & 15 & 14 & Fail \\
\hline 12 & 7.5 & Neurologic & 297 & 12 & 8 & Fail \\
\hline 13 & 7.5 & Neurologic & 189 & 15 & 10 & Pass \\
\hline 14 & 7.5 & Neurologic & 23 & 11 & 9 & No follow-up \\
\hline 15 & 7.5 & Other & 226 & 12 & 11 & Pass \\
\hline 16 & 7.5 & Cardiac & 192 & 21 & 17 & Pass \\
\hline 17 & 7.5 & Neurologic & 288 & 14 & 9 & Pass \\
\hline 18 & 7.5 & Neurologic & 216 & 11 & 10 & Pass \\
\hline 19 & 7.5 & Respiratory (pulmonary embolism) & 96 & 18 & 12 & Pass \\
\hline 20 & 7.5 & Other & 204 & 12 & 8 & Fail \\
\hline 21 & 7.5 & Other & 150 & 16 & 14 & Pass \\
\hline 22 & 7.5 & Septic & 192 & 13 & 9.5 & Fail \\
\hline 23 & 7.5 & Other & 32 & 11 & 11 & Pass \\
\hline 24 & 7.5 & Respiratory (COPD) & 36 & 13 & 13 & Fail \\
\hline 25 & 8 & Cardiac & 250 & 18 & 11 & Fail \\
\hline 26 & 8 & Neurologic & Unknown & 11 & 9 & Pass \\
\hline 27 & 8 & Neurologic & 43 & 21 & 11 & Fail \\
\hline 28 & 8 & Cardiac & 20 & 19 & 16 & Pass \\
\hline 29 & 8 & Respiratory (asthma exacerbation) & 286 & 11 & 7 & Pass \\
\hline \multicolumn{7}{|c|}{$\begin{array}{l}\mathrm{ETT}=\text { endotracheal tube } \\
\mathrm{R}_{\mathrm{aw}}=\text { airway resistance } \\
\mathrm{SBT}=\text { spontaneous breathing trial }\end{array}$} \\
\hline
\end{tabular}

based on alignment of the numbers on the ETT and endOclear device. It was then withdrawn over a period of 5-10 s. Any secretions extracted were collected in the small attached vial and visually inspected. A second pass was performed if necessary to clear all of the secretions from the ETT. Per study protocol, if $\mathrm{R}_{\mathrm{aw}}$ decreased by $3 \mathrm{~cm} \mathrm{H}_{2} \mathrm{O}$ after the initial scraping, this process could be repeated before the next planned SBT if the $\mathrm{R}_{\mathrm{aw}}$ had increased by $3 \mathrm{~cm} \mathrm{H}_{2} \mathrm{O}$ or more since the initial scraping. If $\mathrm{R}_{\mathrm{aw}}$ remained the same or decreased from the initial scraping, a subsequent attempt was not required before the subsequent SBT was performed. The study staff were trained to measure $\mathrm{R}_{\mathrm{aw}}$ and perform endotracheal tube scraping as described above. We also collected data on ETT size, primary diagnosis, duration of mechanical ventilation, and follow-up SBT results (Table 1).

\section{Statistical Analysis}

SPSS (version 23.0, IBM Corp, Armonk, New York) was used to analyze all collected data. A paired $t$ test was conducted to evaluate the mean difference in pre- and post-ETT scraping. A Mann-Whitney $U$ test was used to evaluate the difference in percentage change in $R_{a w}$ between SBT groups.

\section{Results}

\section{Population}

During the study period, 34 subjects were initially enrolled in the study. Twenty-nine subjects completed the study, because 5 subjects either refused the tube scraping 


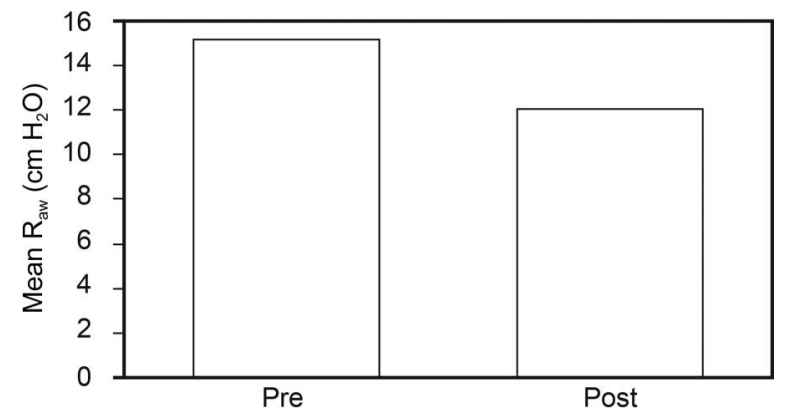

Fig. 1. Mean airway resistance before $( \pm 3.83 \mathrm{SD})$ and after $( \pm 3.19$ $\mathrm{SD}$ ) endOclear treatment.

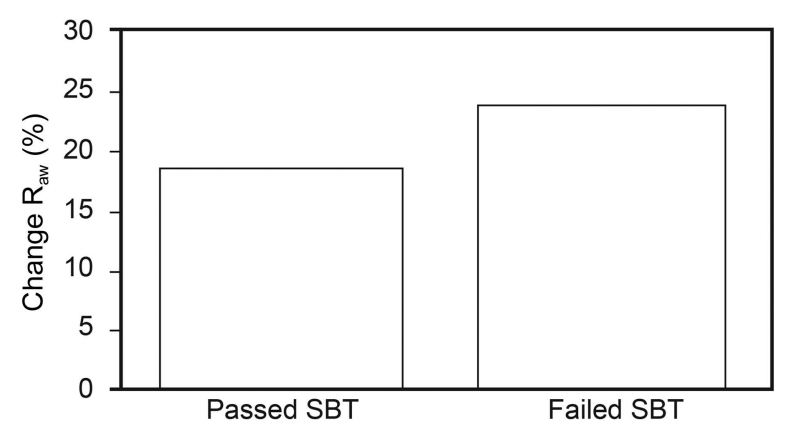

Fig. 2. Median percentage change (decrease) in airway resistance after ETT scraping in subjects who subsequently passed $(19 \%$, interquartile range [IQR] $9-34)$ or failed $(24 \%$, interquartile range $0-35)$ a spontaneous breathing trial (SBT). $P=.78$.

or had missing data noted at the time of final analysis. All adult ICUs were utilized, including the surgical, neuroscience, medical, and cardiac ICUs. Subject disease states were categorized as primarily respiratory, cardiac, neurologic, septic, or other. Nine subjects were categorized as respiratory, of whom 2 had the primary diagnosis of COPD exacerbation, 2 had hypercarbic respiratory failure, 2 had pulmonary embolism, one had pulmonary sarcoidosis, one had lung cancer complicated by pneumonia, and one had an asthma exacerbation.

\section{Airway Resistance and SBT Success}

The mean pre- and post-ETT scraping $\mathrm{R}_{\mathrm{aw}}$ was $15.17 \pm 3.83 \mathrm{~cm} \mathrm{H}_{2} \mathrm{O} / \mathrm{L} / \mathrm{s}$ and $12.05 \pm 3.19 \mathrm{~cm} \mathrm{H}_{2} \mathrm{O} / \mathrm{L} / \mathrm{s}$, respectively $(P<.001)$. The success of subsequent SBT was $48 \%$; however, there was no difference in the percentage change in $\mathrm{R}_{\mathrm{aw}}$ between subsequently passed SBT (18.61\% [interquartile range 8.90-33.93\%]) and failed SBT (23.88\% [interquartile range $0.00-34.80 \%]), \mathrm{U}=78.5$, $\mathrm{z}=-0.284, P=.78$. There were no adverse events associated with ETT scraping (Figs. 1 and 2).

\section{Discussion}

Our findings indicate that ETT scraping can significantly lower the imposed $\mathrm{R}_{\mathrm{aw}}$ due to secretion buildup in the lumen of the endotracheal tube in subjects managed in adult ICUs who are receiving mechanical ventilation. Although statistically significant, the clinical importance of this approximately $3-\mathrm{cm} \mathrm{H}_{2} \mathrm{O} / \mathrm{L} / \mathrm{s}$ drop in mean $\mathrm{R}_{\mathrm{aw}}$ postscraping remains questionable. To assess whether there is a clinical impact, we compared the change in resistance pre- and post-scraping between the study subjects who subsequently passed the SBT and those who failed. We found no difference, which suggests that our targeted $\mathrm{R}_{\mathrm{aw}}$ of $>10 \mathrm{~cm} \mathrm{H}_{2} \mathrm{O} / \mathrm{L} / \mathrm{s}$ was too low or $\mathrm{R}_{\mathrm{aw}}$ has less of an impact on SBT success than previously thought.

It has been reported that the increase in $\mathrm{R}_{\mathrm{aw}}$ can cause respiratory mechanics to deteriorate during an SBT. ${ }^{6}$ The resistive load on the respiratory muscles can become too great for these critically ill patients, resulting in SBT failure. The exact amount of $\mathrm{R}_{\mathrm{aw}}$ that results in the adverse outcome of SBTs is not yet known. Resistive loads may be higher when patients have ETT sizes of $<7.0-\mathrm{mm}$ inner diameter (ID). This suggests that ETT sizes of $>7.0 \mathrm{~mm}$ may impose negligible work if the tube is kept clean and unobstructed. ${ }^{7}$ In our study, one subject was intubated with a 6.5-mm ID ETT, and the others had 7.0-mm ID or larger ETTs. To account for the variable resistance of the different size ETTs used in this study, all SBTs were conducted using automatic tube compensation. This spontaneous mode compensates for the ETT's imposed resistance based on the documented airway size and the patient's peak inspiratory flow. Thus, the lack of difference in SBT success post-scraping is mostly likely not due to variability in ETT size.

In a study by Wilson et al, ${ }^{8}$ it was noted that clinicians may assume that $R_{a w}$ imposed by ETT is minimized when the tube is properly sized for the patient. In fact, clinicians make adjustments to the mechanical ventilator to overcome the imposed $R_{a w}$ when it is suspected. Industry standards of ETT manufacturing regulate diameter consistency at production. It is mandated that ETTs with an ID of $\geq 6.5 \mathrm{~mm}$ have a no-more-than 0.20 - $\mathrm{mm}$ variability. This implies that $\mathrm{R}_{\mathrm{aw}}$ can be predicted, because the ID of the ETT is precisely known. Interestingly, their study found that after intubation, secretions can have a significant impact on the resistance of the ETT. This has previously been thought to be clinically important, since it directly impacts WOB Nearly $50 \%$ of all of the ETTs that they studied had a resistance that was equal to one tube size smaller. The authors suggest that this would be similar to having an ETT with ID of $7.5 \mathrm{~mm}$ that has the resistance of a $6.5-\mathrm{mm}$ ID tube. ${ }^{8}$ Their research suggests that secretions inside of an ETT unnecessarily increase $\mathrm{R}_{\mathrm{aw}}$ and WOB in patients during SBTs and lead to a perceived failure of the SBT. This finding would support the use of ETT scraping to reestablish the original ETT ID to allow a truer weaning assessment. ${ }^{8}$ In addition to an $\mathrm{R}_{\mathrm{aw}}$ of $>10 \mathrm{~cm} \mathrm{H}_{2} \mathrm{O} / \mathrm{L} / \mathrm{s}$ being too low to identify patients with a clinically important 


\section{Evaluation of ETT Scraping on Airway Resistance}

increase in $\mathrm{R}_{\mathrm{aw}}$, the lack of clinical importance may also be related to the short period of time that most patients are undergoing an SBT, typically $30 \mathrm{~min}$, based on department practice. However, the minimum of a $30-\min \mathrm{SBT}$ is consistent with previously published guidelines that were available during the time our study was conducted. ${ }^{9}$

The subsequent SBT pass rate in our study was not improved by lowering the $\mathrm{R}_{\mathrm{aw}}$. Subjects with the largest percentage change in $\mathrm{R}_{\mathrm{aw}}$ after ETT scraping actually failed the SBT at a rate similar to the subsequent SBT pass group $(48 \%)$. The difference in the percentage change from preand post-tube scraping was not statistically significant; however, the findings suggest that a decrease of approximately $19-24 \%$ in $\mathrm{R}_{\mathrm{aw}}$ may not be enough to improve the success of subsequent SBTs. This finding warrants further study to determine the amount of $\mathrm{R}_{\mathrm{aw}}$ improvement with ETT scraping that is clinically relevant.

There are several limitations to this study. First, we did not account for the many reasons that a patient may fail a subsequent SBT. We only ensured that $\mathrm{R}_{\mathrm{aw}}$ was reduced to the lowest amount possible using the endOclear device. Second, our sample size was small and was primarily aimed at assessing whether the $R_{a w}$ could be significantly reduced by ETT scraping in those subjects who failed the initial SBT. Another limitation could be the unknown secretions that remained in the ETT after scraping, since we only decreased mean $\mathrm{R}_{\text {aw }}$ by approximately $3 \mathrm{~cm} \mathrm{H}_{2} \mathrm{O} / \mathrm{L} / \mathrm{s}$. The $R_{a w}$ remained elevated in a majority of our subjects studied. A more significant decrease may have had a greater impact on WOB and improved SBT success.

\section{Conclusions}

The purpose of this study was to assess the impact of ETT scraping on $R_{a w}$ in mechanically ventilated patients. ETT scraping can significantly reduce $\mathrm{R}_{\mathrm{aw}}$ in patients with an $\mathrm{R}_{\mathrm{aw}}$ of $>10 \mathrm{~cm} \mathrm{H}_{2} \mathrm{O} / \mathrm{L} / \mathrm{s}$. This reduction in resistance did not improve subsequent SBT success. Based on our results, we cannot make a recommendation on the use of ETT scraping to improve SBT success in patients with an $\mathrm{R}_{\mathrm{aw}}$ of $>10 \mathrm{~cm} \mathrm{H}_{2} \mathrm{O} / \mathrm{L} / \mathrm{s}$. Future studies are needed to define the level of $\mathrm{R}_{\mathrm{aw}}$ at which ETT scraping would impact SBT success.

\section{REFERENCES}

1. Shah C, Kollef MH. Endotracheal tube intraluminal volume loss among mechanically ventilated patients. Crit Care Med 2004;32(1): 120-125.

2. Mietto C, Pinciroli R, Piriyapatsom A, Thomas JG, Bry L, Delaney ML, et al. Tracheal tube obstruction in mechanically ventilated patients assessed by high-resolution computed tomography. Anesthesiology 2014;121(6):1226-1235.

3. Berra L, Coppadoro A, Bittner EA, Kolobow T, Laquerriere P, Pohlmann JR, et al. A clinical assessment of the Mucus Shaver: a device to keep the endotracheal tube free from secretions. Crit Care Med 2012;40(1):119-124.

4. Pinciroli R, Mietto C, Piriyapatsom A, Chenelle CT, Thomas JG, Pirrone M, et al. Endotracheal tubes cleaned with a novel mechanism for secretion removal: a randomized controlled clinical study. Respir Care 2016;61(11):1431-1439.

5. Hess DR. Respiratory mechanics in mechanically ventilated patients. Respir Care 2014;59(11):1773-1794.

6. McConville JF, Kress JP. Weaning patients from the ventilator. N Engl J Med 2012;367(23):2233-2239.

7. Sharar SR. The effects of artificial airways on airflow and ventilatory mechanics: basic concepts and clinical relevance. Respir Care 1995; 40(3):257-262.

8. Wilson AM, Gray DM, Thomas JG. Increases in endotracheal tube resistance are unpredictable relative to duration of intubation. Chest 2009;136(4):1006-1013.

9. MacIntyre NR, Cook DJ, Ely EW Jr, Epstein SK, Fink JB, Heffner JE, et al. Evidence-based guidelines for weaning and discontinuing ventilatory support: a collective task force facilitated by the American College of Chest Physicians, the American Association for Respiratory Care, and the American College of Critical Care Medicine. Chest 2001;120(6 Suppl):375S-395S. 